\title{
Nuclear Crisis Preparedness Lessons Learned from Fukushima Daiichi
}

\author{
Geneviève Baumont
}

\begin{abstract}
Before the Fukushima Daiichi accident in 2011, the French Institute of Radiological Protection and Nuclear Safety, IRSN, was little-known to the French public. On the whole, French nuclear safety procedures are complex and the public is largely unaware of them. Moreover, communication was difficult because IRSN had to gain public trust as a result of the negative memory associated with the communication approach taken by the government in 1986 when managing the Chernobyl fallout. This communication approach led to a loss of public trust in official bodies in general. During the Fukushima Daiichi crisis, the importance of communication in such a period was largely emphasized, although France was absolutely not at risk. IRSN operations were adapted in order to explain the risks linked to this disaster to the media, companies, and French citizens. Two hundred IRSN staff members answered queries non-stop for 6 weeks, exploring the new ways of communication and interaction offered by social networks. In the years after the disaster, experts from institutions such as IRSN examined all the post-accident situations where Japanese citizens and expatriates turned to buying Geiger counters, developing new sensors to make measurements and becoming addicted to the internet to find information of all kinds, in an attempt to forge their own opinion about the importance of nuclear risks. This is the reason why IRSN developed a strategy not only to inform people with the basic useful knowledge in such situations but also to try to "empower people" by helping them to measure and share their data. The goal is to multiply the number of people aware of what radioactivity is and its associated risks, capable of measuring the level of radioactivity and interpreting it. This strategy requires communication tools and partners. IRSN is associated with IFFO RME, the French Institute of trainers on Major risks and the environment, a body with close links to the national education ministry.
\end{abstract}

G. Baumont $(\bowtie)$

Institut de Radioprotection et de Sûreté Nucléaire (IRSN), Fontenay-Aux-Roses, France e-mail: baumont.g@ orange.fr

(C) The Author(s) 2018

M. Bourrier and C. Bieder (eds.), Risk Communication for the Future, SpringerBriefs

in Safety Management, https://doi.org/10.1007/978-3-319-74098-0_4 
Keywords Fukushima - Crisis - Communication • Ionizing radiation Contamination - Citizen science - Public information - Media - "Safecast"

\section{Communication Challenges Before the Fukushima Accident}

Created in 2002, IRSN is a public body with industrial and commercial activities, operating under the joint supervision of the Ministers in charge of Energy, Environment, Health, Defence, and Research. The main missions of the Institute are Research, Assessment, and Public service missions including Public Information. The fields of activity are broad, covering nuclear safety, radioprotection of workers, radioprotection of the population and the environment, radiation protection of workers and the public in nuclear medicine, emergency preparedness and post-accident operational support, security and control of nuclear sensitive materials, and security of nuclear facilities.

\section{Nuclear safety organisation in France}

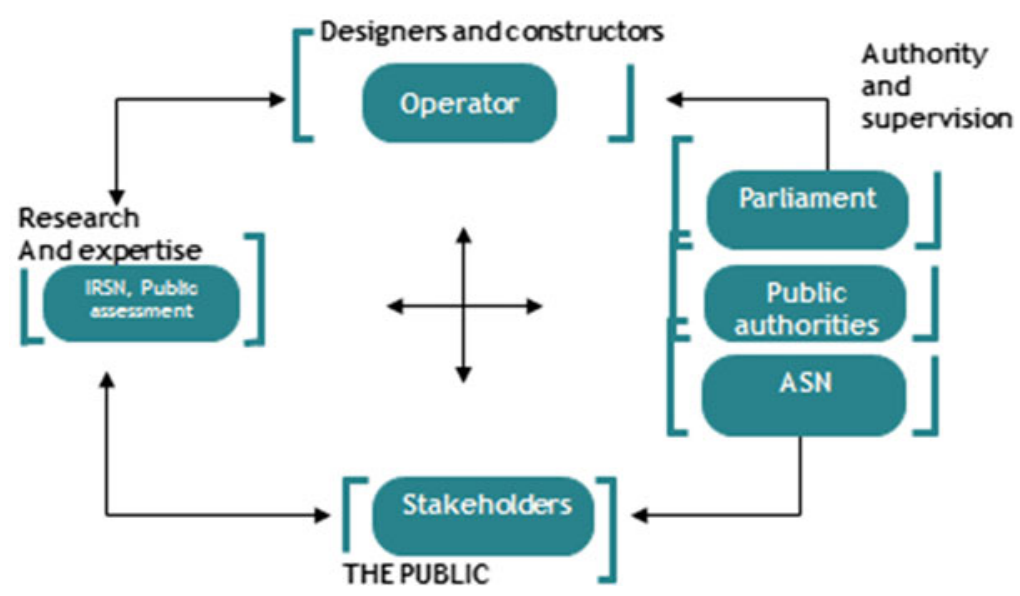

For IRSN, before the Fukushima crisis, communication was a challenge, because in April 1986, government communication when managing the Chernobyl fallout led to a loss of public trust in official bodies (even today more than $63 \%$ of French people still do not trust the Nuclear Safety Authority (IRSN 2011a, 2012a)). The general public believe that "the government lied," with the most symbolic sentence used in France to resume the communication at this period being "The fallout cloud stopped at the border."

The strategy of IRSN's communication department before the accident was to develop an independence of judgment inside the Institute and at the same time to 
increase IRSN's visibility and confidence in it from the media and the general public. All IRSN experts and researchers were involved to reach this objective through, for example, media training to better understand the ins and outs and the constraints of the media.

For the above reasons, in 2010, IRSN also developed specific actions to inform the public with the basic useful knowledge for crisis situations. The main thrust of this strategy is to reinforce background knowledge in high schools and among the general public encountered during science fairs. IRSN and its experts regularly provide interactive lectures for high schools based on a presentation freely distributed to teachers who integrate nuclear science into their program.

\section{How Did IRSN Experience the Fukushima Daiichi Crisis?}

During the Fukushima Daiichi crisis, the Institute provided accurate real-time information to local authorities, the media, the public and civil society, mobilizing experts and the communication unit (IRSN 2012a). Institutions such as IRSN were facing an unprecedented situation. With requests coming from all sides, the institute prepared daily electronic bulletins, summarizing our analysis of the state of Japanese nuclear plants and the consequences for the population and the environment. Nearly, all of the ministerial offices subscribed to these bulletins. IRSN also participated, each morning, in meetings of the French inter-ministerial emergency response group, led by the Secretary of the Defence and National Security, reporting to the Prime Minister. The Institute was called upon by the Parliamentary office of scientific and technological evaluation, which provides information to Parliament and guides its decisions. The simulation of the radioactive plume from Fukushima made available online shortly after the accident was followed all over the world, as were the reports on the contamination and environmental effects on land and in the sea (Video IRSN 2012). Consequently, for 6 weeks, 200 IRSN staff members answered questions non-stop from companies and French citizens to explain the risks linked to this disaster.

The health impact and environmental impact units quickly proved to be essential. The health impact unit set up base in an IRSN conference room. Eight full-time experts, assisted by 16 experts working in rotation, responded to 1300 requests received in just 4 weeks from physicians and Occupational Health Physicians, the press, and the general public. They were especially busy when the contaminated air masses reached France. The unit also scanned 250 people returning from Japan (journalists, expatriates, airline pilots, etc.) with a whole-body counter to check them for contamination and provided 300 passive dosimeters to people headed for Japan. The importance of communication in such a period was largely highlighted, even if France was absolutely not at risk. 


\section{Social Media and Media Pressure During the Crisis}

From March 11 to March 31, 2011, social media demonstrated its incredible power. On Twitter, for example, the hashtag \#Fukushima was used over 500 million times between March 11 and April 11, 2011. Already on March 11, the day of the accident, an increase of 33 million tweets per day was recorded, and the creation of 572,000 new accounts was seen from March 12, 2011 on. 1840 people subscribed to the IRSN Twitter account @ suretenucleaire (on April 15, 2011). In France, the Fukushima nuclear accident entirely occupied the attention of all key players in the nuclear industry, politicians, and the media for more than 5 weeks.

The communication team organized press conferences and interviews with experts in response to some 1365 media requests. This meant responding to more than 100 interview requests per day, with mandatory deadlines, and using language that was easily understandable. For example, the French newspaper Le Monde wraps up at 10:30 am: they needed an expert by 9 am at the latest. Radio stations needed regular information bulletins, and television stations needed content for the $1 \mathrm{pm}$ and $8 \mathrm{pm}$ news programs. So, three representatives were quickly named for different fields: facility safety, environment, and health. Their greatest difficulty was to provide information in real time. The following data published by the agency Kantar Media, a French media analyst, proves the extreme media hype even in France due to the Fukushima accident: this event was mentioned more than 14,000 times in French press, radio, and television. IRSN was mentioned more than 5000 times.

\section{Main Facts of the Crisis Management Strategy}

11 March: 7:00 am Earthquake in Japan. At $11 \mathrm{~h}$, the IRSN Technical Emergency and Response Center is activated, and at $5 \mathrm{pm}$ a paper on the earthquake is published on the IRSN website.

12 March: 8:50 am reactor 1 exploded. At $8 \mathrm{pm}$, a paper on the situation is published on the IRSN website.

14 March: 3:30 am reactor 3 exploded. At 4 pm, the Japanese measurement results from the environment are available on the IRSN website.

15 March: 0:05 am reactor 3 exploded, reactor 4 is burning, first media conference in IRSN, first FAQ publication.

16 March: the Prime Minister, F. Fillon, announced in the National Assembly that data on the level of contamination in the environment are available on the IRSN website.

17 March: the first modeling of the fallout cloud in Japan is published on the IRSN website.

19 March: the modeling of the fallout cloud across the world is published on the IRSN website.

22 March: the cloud with very few radioactive particles reached France; consequently, the number of visits to the IRSN website reached a significant peak. 
The IRSN documents in French and English used during this period are published on the IRSN web pages, FAQ and Earthquake and nuclear crisis in Japan in 2011 (IRSN 2011a).

\section{The Website Success}

The chart below shows the increase in the number of website visits during Fukushima crisis. From March 13-17, more than 50 technical suggestions proposed by the public to solve the situation were posted to the IRSN contact box. IRSN's website infrastructure was modified several times, from 2 to 20 servers, to address the increasing number of visits. The webmaster was on duty day and night and slept only a few hours a day, because there was no one to take over from him. Today, two webmasters will be able to replace each other in case of an emergency situation.

The IRSN (2011b) contact box received 1054 requests, not only from French public but also worldwide. More than 1000 questions were asked by the public. The following graph shows which topics were of most concern for the public, over time.

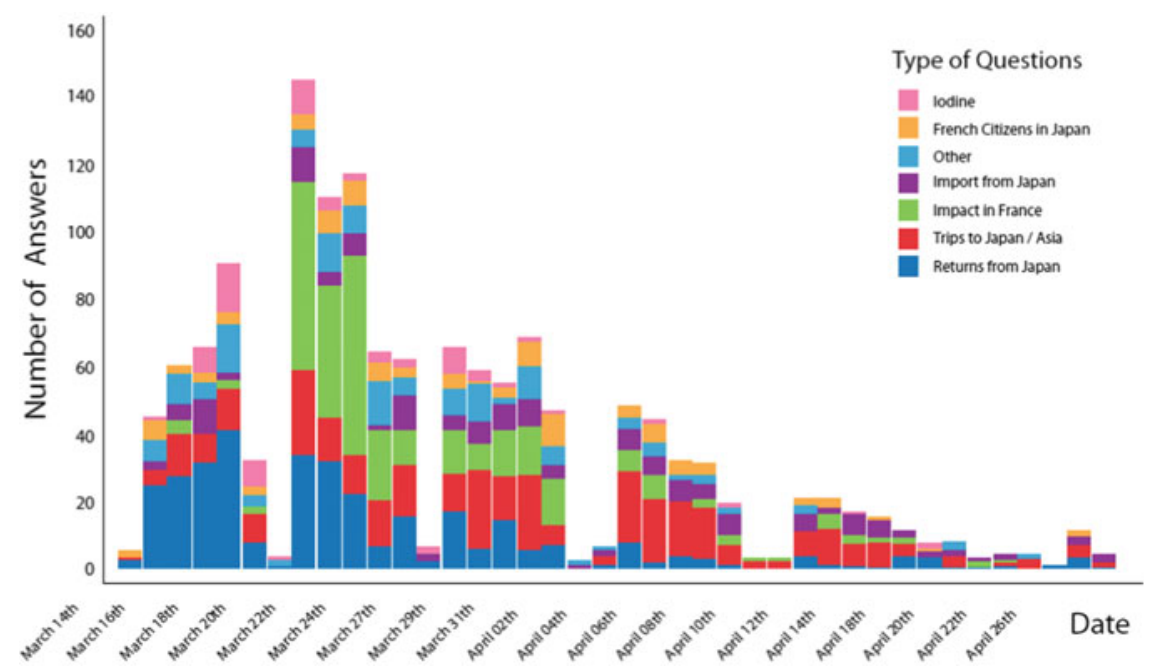




\section{Why Was Communication "Successful”?}

With a disaster such as the Fukushima nuclear accident, it is of course awkward to speak of "successful" communication by IRSN, but it was recognized that, for the first time, IRSN had increasing media attention, confidence, and website engagement. Naturally, the priority of Japanese experts was emergency response management to recover the situation and to deal with the safety of the population and workers of the plant affected.

As the IRSN experts were not directly involved in emergency response management, the experts were able to concentrate only on the scientific and technical assessments by closely following the daily situation of the NPP. The assessments, based on 30 years of research and experience feedback in the nuclear field, served to advise the French public authorities and to inform the public.

The technical and scientific competencies of IRSN staff (200 people during more than 5 weeks) were therefore available simply for communication purposes in the form of a $24 \mathrm{~h}$ information service. Five spokespersons were continuously available for the media. And from the beginning of the nuclear crisis, the IRSN experts never minimized the Fukushima accident. This was also the result of a long-term strategy of communication implemented by IRSN over more than 10 years, based on a strong relationship and understanding between scientific experts and the communication team.

Despite the clear and trustworthy information given by IRSN and despite the fact that there were no direct casualties in Japan due to the nuclear accident, public surveys showed that this did not stop French citizens losing confidence in nuclear power. ${ }^{1}$

\section{How the Fukushima Accident Influenced the Communication Approach Worldwide}

The shock of the earthquake, followed by a tsunami and the subsequent nuclear disaster, made the communication situation extremely difficult. Further difficulty was caused by the local population's lack of preparation and education concerning

\footnotetext{
${ }^{1}$ The proportion of respondents to IRSN's annual risk perception survey answering "no" to the question "Do you trust the French authorities concerning the risk mitigation actions for citizens" rose from 39 to $42 \%$ concerning nuclear power plants, and from 63 to $64 \%$ for radioactive fallout from the Chernobyl accident between 2011 and 2015 (IRSN 2011a, 2012a).
} 
nuclear risks. A lot of the extra stress and trauma experienced by this population, as well as their dramatic stigmatization by certain parts of Japanese society but also by the rest of the world, could have been avoided by better public education.

In their article, Yamashita and Takamura (2015) draw attention to " a lack of or inadequate knowledge and education on radiation protection and radiation health risk management has evoked a serious confusion and adverse reaction on information from the different communication tools such as social media that low-dose radiation effects still contain uncertainty, thus complicating risk perception of the general public."

The great difference between the communication during the Chernobyl nuclear accident and that of the Fukushima accident demonstrates how important it is to query and review the information and communication approaches not only at European level but also worldwide, in particular at IAEA OECD.

The experience feedback of the communication behavior during/in the aftermath of such an accident from the nuclear regulatory bodies and the different agencies were discussed in workshops with the aim of drafting guidelines in order to try and harmonize practices, taking into account the New Information Technologies (NIT) used by the public, in particular social media and new smartphone applications.

These reviews underline the influence of social media in the context of a nuclear accident. One IAEA document mentions the following:

More casually, social media is described as a landscape of internet platforms where users can interact easily and share ideas, opinions and information. With social media, information dissemination - be it personal, commercial, or official government information - has become easier, faster, cheaper, and accessible to more people. One can target the audience in ways that weren't possible before. (Sköld and Feldman 2014)

Notably, the same document notes that: "Statistics suggest that about $100 \mathrm{~h}$ of video are uploaded to YouTube every minute, 500 million tweets are sent daily, 1.6 million public photos are uploaded to Flickr per day and 30 billion pieces of content are shared on Facebook every month."

Most reports state that the main challenge in using social media is assuring not only data quality but also evaluating the credibility of sources, dealing with the transitory and voluminous nature of social media information, data management, and ethics.

In 2014, the IAEA published in their proceedings papers this analysis: the Efficacy of Social Media as a Research Tool and Information Source for Safeguards Verification (Sköld and Feldman 2014). It gives guidelines on communication with the public in a nuclear or radiological emergency (IAEA 2012). Later, in 2015, they published reference document which provides a method for developing a communication strategy dedicated to a nuclear or radiological emergency (IAEA 2015). 


\section{From Communication to Public Empowerment}

Lessons learned from the Fukushima Daiichi NPP crisis and its aftermath have confirmed that lack of knowledge and understanding during emergencies is extraordinarily stressful and will have negative psychological consequences, not only for people directly affected but also for those witnessing it from a distance. For an individual, improved understanding changes their perspective, transforming them from feeling like a helpless victim into an actor who has some degree of power over the situation. One of the challenges of a nuclear accident is to prepare for the post-accident phase, and to be adequately aware of the wider consequences that can be produced by the accident. The population most affected by nuclear fallout may be obliged to evacuate or to live in contaminated areas with many constraints. Because citizens in this situation will likely need to carefully follow the recommendations of authorities in order to limit their individual exposure, it is very important that they trust decision-makers. Taking their own readings [of radiation] helps citizens become knowledgeable active participants in the safety dialogue. Other local citizens as well as consumers worldwide who might be considered less directly affected by radioactive contamination nevertheless have a valid stake in accurate information. Lack of knowledge, mistrust of authorities, and receptivity to misinformation can lead many to erroneously consider a country which in fact has suffered hazardous contamination in only a limited zone to be contaminated in its entirety. As has been seen after the Fukushima disaster, this can lead to product boycotts and lengthy embargos, particularly for foodstuffs, but also against travel and tourism (IRSN 2012b). The nuclear accident in Japan showed that these boycotts and embargos can have a significant economic impact and can lead to an entire country facing unexpected reputational challenges, leading to a deterioration of the living conditions for the whole country. This economic impact has been developed by IRSN in "Methodology of IRSN accident cost estimates" and in Pascucci-Cahen and Momal (2012).

In the wake of the Fukushima Daiichi NPP disaster, citizen-science-based radiation data collection efforts have proven very important in filling information gaps for the public. The technical abilities and organization of citizen groups have been increasingly recognized by governmental institutions, first responders, and international bodies, many of whom have expressed interest in integrating citizen efforts into disaster response plans (Brown et al. 2016a, b).

The best description of this challenge from a communication perspective was given by the Canadian health ministry's document called "The Health Canada Policy Toolkit for Public Involvement in Decision Making" (Health Canada 2000). The document is an excellent guideline on how to reach a satisfactory degree of public involvement in decision-making. 


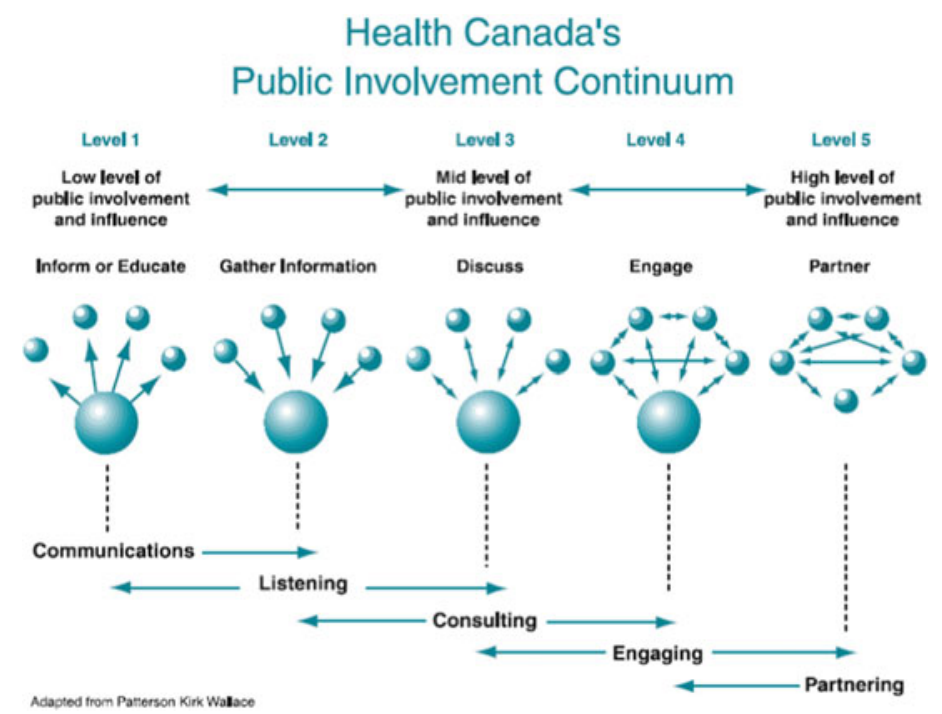

The different kinds of public participation and the different positions which could be adopted by a government communication team with the general public are clearly summarized in the above diagram. During the Fukushima crisis, IRSN mostly informed (level 1, communication) and listened to people (level 2, contact box, dialogue with journalists, expatriates, airline pilots, and health experts).

The review of new communication practices that appeared after the Fukushima accident shows not only the influence of NITs but also the active participation of Japanese citizens in data collection and sharing. Slowly but surely, this trend is becoming global and citizens may also be considered as partners of institutions when they begin to measure radiation by themselves (level 5).

This is well expressed in the paper by Macfarlane "The nuclear reactor accident ... led to a loss of trust in nuclear power around the globe and acutely in Japan. The reactions of the public in Japan and other countries, such as the United States, and the governmental reactions to the accident offer an opportunity to learn ways to improve safety and communication during and after a nuclear accident" (Macfarlane 2016).

Since the Fukushima crisis, many ordinary citizens, organized in different groups or associations have engaged in radiation measuring with new devices they designed themselves, and have shared their data over the Internet. "Radiation watch" sensor or "Radioactivity counter" applications can be bought by citizens to measure radioactivity in their environment.

The project "Safecast" is a prime example of citizen mobilization (Brown et al. 2016a, b). Safecast is an international, volunteer-based organization devoted to monitoring and openly sharing information on environmental radiation and other pollutants. It was formed on March 12, 2011, one day after the start of the Fukushima Daiichi NPP accident, in response to what several official reports on the 
disaster have criticized as the chaotic nature of TEPCO, inter-agency, and inter-governmental communication. Since 2011, Safecast has implemented participatory, open-source, citizen-science-centered radiation mapping solutions developed through a process of collaborative open innovation. Safecast develops sensors and a variety of other innovative hardware and software for visualizing environmental measurement data. The group seeks to provide people who are concerned about environmental and nuclear issues with tools they can use to build alternative open means of measurement and communication, which can be easily shared and built upon by others. Five years after the start of the Fukushima disaster, Safecast volunteers have built and deployed hundreds of radiation sensors worldwide and have amassed the largest open data set of radiation measurements to date.

As it is clearly explained on their website, they are neither pro- nor anti-nuclear: "Safecast is pro-data". "Radiation and its environmental and health effects are issues which are fraught with deep-seated controversy. Unfortunately, it has been difficult until now to find radiation data which truly has been free of bias, or of the perception of bias in favor of one ideological position or another. From the outset, Safecast has not sided with either the pro or anti-nuclear camps, and has striven to demonstrate the advantages to science and to the public of having an independent organization devoted solely to providing the most accurate and credible data possible. Safecast is "pro-data." Independence, transparency, and openness are essential for us and the key to our credibility. Safecast was quickly recognized in Japan and abroad as a reliable and unbiased source of environmental information which citizens can use when making decisions" (SAFECAST 2017).

Their tool and their mapping (more than 35 million pieces of data, mostly in Japan) are the result of the engagement of the Safecast members as simple but engaged citizens.
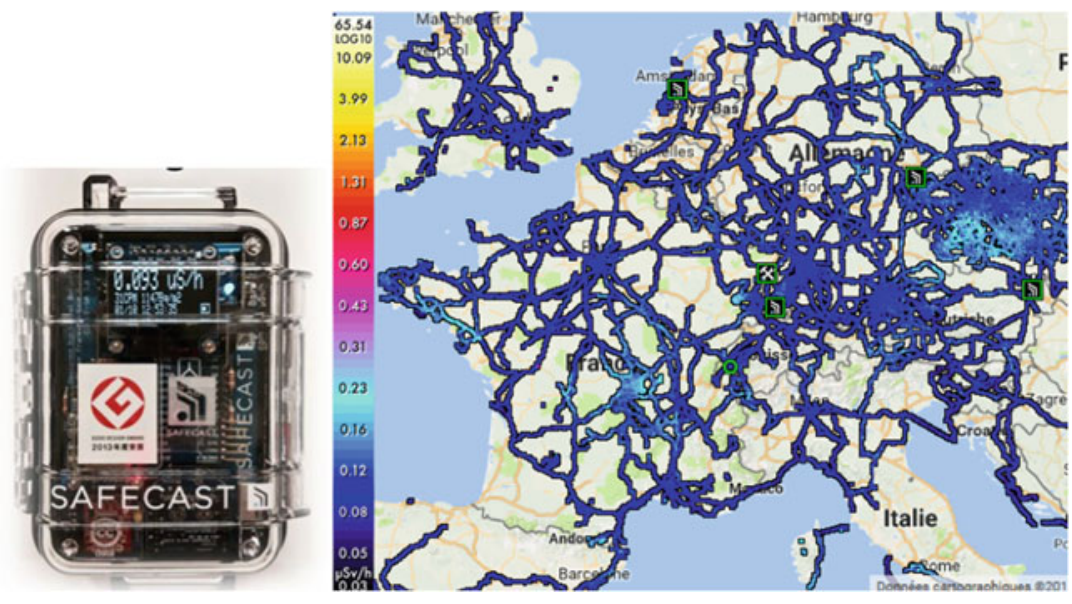
In Japan, these new competences were recognized by Abe Yasuhito: "Since the Fukushima nuclear accident, many ordinary citizens have engaged in DIY (do-ityourself) radiation measuring, and have circulated the data over the Internet. Considerable effort has been invested in studying citizen science movements in previous manmade environmental disasters. But as has been often emphasized in the case of 3.11 2011, a great variety of groups of people have generated all sorts of information on nuclear risks, using the Internet and social media. This is the first "known" major nuclear disaster since the advent of the Internet and social media. Whereas citizens engaged in generating information about nuclear risks after nuclear disasters such as Chernobyl, 3.11 opened the door for an alternative kind of collective production and circulation of nuclear risk information via the Internet and social media" (Yasuhito 2014).

This is described by the sociologist Daniel Aldrich as a "citizen reaction and the evolution of communication in a bottom up process: "Beyond economic concerns from the business community, several new initiatives show how Japan's civil society has been energized by this tremendous tragedy. The Safecast project ... embodies a new focus on "citizen science"-that is the participation of everyday residents as volunteers in data collection, technical measurement, and analysis in fields as ecology, biodiversity and astronomy. Participants in such collaborative projects work together often using web based platforms and affordable instrumentation, to achieve results that lone researchers in highly funded laboratories would not be able to accomplish" (Aldrich 2012).

It is interesting to note that the people behind Safecast worked in technical and scientific fields not even closely related to the radiation protection field before March 2011, but they were recently able to write a scientific publication in the peer-reviewed Journal of Radioprotection to present their approach and experience (Brown et al. 2016a, b).

In the Czech Republic, this new opportunity for participation based on these new tools and on citizen engagement was well-received by the Ministry of the Interior. Within the framework of security research, a program has been established which aims to improve public safety by introducing radiation monitoring systems at several levels, including institutions, schools, and citizens, in accordance with current international trends. The program is entitled "Radiation Monitoring Network for Institutions and Schools to Assure Early Awareness and Enhancing Safety of Citizens (RAMESIS)".

Through this program, tools for measurements plus the applications for receipt, storage, administration, and publication of radiation monitoring results are analyzed, projected, developed, and procured. The system is implemented at selected institutions and schools, with the provision of training and informational materials for improving overall understanding of radiation issues.

The project is running from 2015 to 2019, under the guidance of the National Radiation Protection Institute (SURO). The Safecast bGeigie Nano was chosen for mobile monitoring. SURO purchased approximately 30 units and distributed them to selected schools and institutions. SURO also prepared manuals and user guides for performing mobile monitoring and for sending the data to the central workplace. 
It developed user-oriented, open-source based software modules to enable users to display their bGeigie nano-measurement results directly on online and offline maps. SURO collects the results of field measurements from all the users participating in this project and supervises their submission to the safecast.org database for visualization.

\section{A New Perspective for the IRSN Communication Department}

As already mentioned, these new challenges for increasing citizen participation and education could easily be incorporated into IRSN's existing practices as this was already partially implemented in the regulatory context.

Indeed, the following laws and European conventions promote the development of a transparent communication strategy for the general public and the active participation of citizens:

In the French law N 2004-811 of August 13, 2004, the Civil Protection Modernization Act aims to make the citizen a major player in civil security by spreading the risk culture among younger generations, in crisis situations, and recognizing the role and missions of associations.

This act, largely inspired by the European Aarhus Convention on Public Information (June, 25 1998) based on the following three pillars: right to know, right to participate, and right to justice, has been further adapted to French law.

This has been even better formulated in the Act on Transparency and Security in the Nuclear Field (2006) stipulating that transparency in the nuclear field consists of the set of provisions adopted to ensure the public's right to reliable and accessible information on nuclear safety and security.

For an individual, understanding the situation and seeing the perspectives makes this person an actor of the situation. Communication needs to give meaning during the nuclear crisis phenomenon because every person is entitled to be informed of the risks related to nuclear activities and their impact on personal health and security as well as on the environment, and to be aware of discharges from nuclear installations and their consequences. That is why, it is important that communication during a nuclear crisis situation seeks to increase the individual and collective understanding of the development of the accident, to maintain the trust of the population throughout the incident.

For France, the other challenge is to prepare the post-accident phase, to be aware of the stakes related to the accident and to try to minimize the cost of the direct and indirect consequences. This cost depends greatly on the societal response and the resilience factors strengthened inside the society before the accident: providing long-term information, partnering, and empowerment of citizens is essential for that objective. One way to reduce this kind of consequence would be to give citizens the tools to measure by themselves the level of radiation in their own environment 
although, of course, IRSN's experts and communication team could play a useful role in promoting understanding of these measurements.

Transparent communication also avoids fear and panic reactions from outsiders and reduces erratic mass behavior like boycotts of local products, boycotts of traveling to the country concerned, etc., and will consequently help to mitigate the economic and social costs of the accident on the food supply, the loss of image, etc.

After the Fukushima crisis, the French authorities and their technical support organization, IRSN, were well aware of the necessity to work toward citizen participation and were a nuclear crisis to happen in France, and they decided that the way to build public confidence was to improve the communication strategy by regular and transparent communication, educational programs for elementary schools, high schools, and universities, public events such as open days and exhibitions, public consultations at the local and national level via well-structured systems. An exhibition was specially designed by IRSN and ASN to inform the general public about radioactivity and covers several nuclear topics such as Radiation Basics, Nuclear Power Plants, Nuclear Accidents, Health Effects of Ionizing Radiation, Nuclear Medicine, Fuel Cycle, and Waste Management. The target audience is the population living in the vicinity of nuclear installations, the population living in areas where radon is likely to be found, professionals likely to be exposed to radioactivity, secondary school, and university students. For example, high schools can choose from 80 available stand-up posters to illustrate every possible question about radiation, and different tools for measuring radon and natural radioactivity are put at the disposal of the schools. In 2016, 17 high schools presented an exhibition, using these freely provided support materials.

But as a complementary action, they also seek to "empower the French public" by measuring and by sharing their data on a common map. The goal is to multiply the number of people aware about what radioactivity is and the associated risks, capable to measure the level of radioactivity and interpret this correctly.

In addition, IRSN suggests using different tools for measuring radon (Canary) or natural radioactivity (Safecast tools) on their territories in order to become more aware about the level of natural background of radioactivity, and on the radioactivity units (the previously unknown units Becquerel (bq), "Sievert" and "Gray" unfortunately became very familiar to Japanese people). IRSN experts monitor the studies carried out by students. For example, the blog shows the kind of results achieved by three high school students in Vichy (Sauvage et al. 2015).

In addition, to reinforce citizen empowerment, IRSN is adding a new element to its strategy. IRSN decided to partner with universities, with IFFO RME, the French Institute of trainers on Major risks and environment working adequately and in close collaboration with the national education ministry and with the association Planet Sciences. This partnership is called "Open Radiation". The idea is to have all citizen measurements, regardless of the sensor used, shared on a map and commented on a specially designed website. This website is currently under development. 


\section{Conclusion}

The Fukushima accident gave fresh impetus to the thinking related to crisis management and particularly to the issues of communication and relations with citizens in such a period. Today more than ever, we live in a knowledge-based society and we are no longer able to ignore the growing desire from the public to have access to information.

The existence of social media means that information is available anywhere and everywhere and news travels fast. Social media have therefore taken on a growing importance for the nuclear agencies and imposed on them their speed, their multiple sources, and modes of treatments. Other competences, such as community managers, have appeared. The widened range of information channels imposes new modes of information besides the traditional reports on websites: Facebook page, Twitter accounts, a dedicated web page, videos on YouTube, etc.

In order to maintain trust, communication should be clear, timely, regular, and efficient. However, communication alone is not sufficient anymore. The new communication strategy on risk-related matters involves nurturing the ability of citizens to measure radioactivity themselves and become experts. So, a stronger partnership with this kind of citizens can help to increase confidence and trust.

A citizen data and information-sharing network offers a great opportunity to foster confidence today and to be a valuable aid for crisis management tomorrow. The project "Safecast" is proof of this and promotes the concept of a new form of citizen involvement by measuring and, together with the nuclear agencies concerned, building up a statistical base, thanks to the large number of measurements. In an emergency, governments or power companies will not have the manpower to provide the kind of radiation measurement information the public wants, not only around the accident site but from anywhere else, including abroad. In this case, a worldwide citizen network can be a great support.

At IRSN, faced with this new situation concerning the project "Safecast" or other similar citizens' networks, some experts immediately had a very positive reaction right away; others questioned the reliability and quality of measurements by non-professionals and expressed a certain criticism with the "radiation measurement priesthood" as one of the "Safecast" members described them. However, after discussions about the pros and cons, most crisis managers become increasingly interested, as these measurements could provide a huge set of data at very early stages after a nuclear accident. Of course, it will still take time to convince the entire nuclear scientific community!

Nevertheless, helping citizens and in particular the younger generation gather baseline data to show what is "normal", and engaging them in an ongoing educational process has become a very important part of the IRSN communication strategy. IRSN may be considered one of the trendsetters by combining hard sciences and soft sciences for communication and citizen empowerment purposes, and this trend is starting to spread worldwide, helping to build a better relationship between citizen groups and emergency responders in nuclear agencies. 
Acknowledgements The author would like to thank Marie Pierre Bigot, director of the Communication Department of IRSN, who managed the crisis communication when Fukushima Daiichi accident occurred. This paper describes the challenges she faced.

\section{References}

Aldrich, D. (2012). Post-crisis Japanese nuclear policy: From top down directives to bottom-up activism...Analysis from the East West center. $\mathrm{N}^{\circ} 103$, Jan 2012. Retrieved from www. eastwestcenter.org/sites/default/files/.../api103.p.

Brown, A., Franken, P., Bonner, S., Dolezal, N., \& Moross, J. (2016a). Safecast: Successful citizen-science for radiation measurement and communication after Fukushima. Journal of Radiological Protection, 36(2), S82.

Brown, A. Baumont, G. Kuča, P., \& Helebrant, J. (2016b). Citizen-based radiation measurement in Europe: Supporting informed decisions regarding radiation exposure for emergencies as well as in daily life. In RICOMET Conference Poster. Retrieved from http://ricomet2016.sckcen.be/ / mdia/Files/Ricomet2016/Day1/PP110\%20Brown.pdf?la=en.

Health Canada. (2000). Health Canada policy toolkit for public involvement in decision making. Retrieved from http://www.hc-sc.gc.ca/ahc-asc/alt_formats/pacrb-dgapcr/pdf/public-consult/ 2000decision-eng.pdf.

IRSN. (2011a). Baromètre Irsn 2011. Retrieved from http://www.irsn.fr/FR/IRSN/Publications/ barometre/Documents/IRSN_barometre_2011.pdf.

IRSN. (2011b). FAQ during Fukushima accident. Retrieved from http://www.irsn.fr/FR/ connaissances/Installations_nucleaires/Les-accidents-nucleaires/accident-fukushima-2011/ crise-2011/faq/Pages/sommaire-faq.aspx.

IRSN. (2012a). Baromètre Irsn 2012. Retrieved from http://www.irsn.fr/FR/IRSN/Publications/ barometre/Documents/IRSN_barometre_2012.pdf.

IRSN. (2012b). Repères 12 special report Fukushima, first lessons learnt. Retrieved from http:// www.irsn.fr/EN/publications/thematic/fukushima/Documents/IRSN_Reperes12_Fukushima_ EN.pdf.

IAEA. (2012). Communication with the public in a nuclear or radiological emergency. Retrieved from http://www-pub.iaea.org/MTCD/Publications/PDF/EPR-Communcation_web.pdf.

IAEA. (2015). Method for developing a communication strategy and plan for a nuclear or radiological emergency. Retrieved from http://www-pub.iaea.org/MTCD/Publications/PDF/ EPR-CommPlan2015_web.pdf.

Macfarlane, A. (2016). Radiation and regulation in a post-Fukushima World. Health Physics, 110 (2), 118-122.

Pascucci-Cahen, L., \& Momal, P. (2012). Methodology of IRSN accident cost estimates. In Eurosafe, 2012. USA: Mimeo.

SAFECAST. (2017). http://blog.safecast.org/.

Sauvage, A., Alkan, G, \& Vaupres, G. (2015). Quand les citoyens s'emparent de la mesure. Retrieved from http://radioactivite-auvergne.blogspot.fr/.

Sköld T, \& Feldman Y. (2014). The efficacy of social media as a research tool and information source for safeguards verification. Retrieved from https://www.iaea.org/safeguards/ symposium/2014/home/eproceedings/sg2014-papers/000082.pdf.

Yasuhito, A. (2014). Safecast or the production of collective intelligence on radiation risks after 3.11. The Asia-Pacific Journal, 12(7), 5, Japan focus, Feb 2014. Retrieved from http://apjjf. org/2014/12/7/YasuhitoAbe/4077/article.html..

Yamashita, S., \& Takamura, N. (2015). Post-crisis efforts towards recovery and resilience after the Fukushima Daiichi Nuclear Power Plant accident. Japanese Journal of Clinical Oncology, 45 (8), 700-707. 


\section{Videos}

IRSN. (2012). Contamination of environment. Retrieved from http://www.irsn.fr/EN/publications/ thematic-safety/fukushima/Pages/2-fukushima-understanding-environment.aspx.

Open Access This chapter is licensed under the terms of the Creative Commons Attribution 4.0 International License (http://creativecommons.org/licenses/by/4.0/), which permits use, sharing, adaptation, distribution and reproduction in any medium or format, as long as you give appropriate credit to the original author(s) and the source, provide a link to the Creative Commons license and indicate if changes were made.

The images or other third party material in this chapter are included in the chapter's Creative Commons license, unless indicated otherwise in a credit line to the material. If material is not included in the chapter's Creative Commons license and your intended use is not permitted by statutory regulation or exceeds the permitted use, you will need to obtain permission directly from the copyright holder.

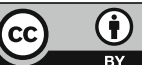

